\title{
The European heat wave 2003: early indicators from multisensoral microwave remote sensing?
}

\author{
A. Loew (1), T. Holmes (2), and R. de Jeu (2) \\ (1) Max-Planck-Institute for Meteorology, The Land in the Earth System, Hamburg, Germany (alexander.loew@zmaw.de), (2) \\ Faculty of Earth and Life Sciences, Vrije Universiteit Amsterdam, Amsterdam, THE NETHERLANDS
}

An extreme heat wave affected large parts of Europe in 2003 with severe socioeconomic impacts. The extreme warm weather conditions lasted over a couple of months with positive temperature anomalies of $5^{\circ} \mathrm{C}$ for large parts of Europe. Simulations of the event using regional climate models revealed that a pronounced precipitation deficit in the beginning of the year, together with an early onset of the vegetation, resulted in a severe deficit of the soil water content. This amplified the course of the heat wave due to an increasing sensible heat flux from the land surface.

The monitoring of temporal and spatial dynamics of soil water content can be accomplished using remote sensing based techniques. The present paper addresses the question whether there have been early indicators for the low soil water content using either physically based land surface modeling or remote sensing based monitoring techniques. The course of the spring surface soil moisture evolution is investigated using observations from two different microwave remote sensing sensors. An intercomparison of the high resolution data from the European ENVISAT satellite and coarse resolution data from the AMSR-E mission is made. Remote sensing derived soil moisture products are compared against the results from a deterministic land surface model. The model enables to relate the year 2003 anomalies to a long term $(30 \mathrm{yr}$ ) climatology. Comparisons of the remote sensing derived soil moisture dynamics in 2003 are compared against a multiyear climatology. The results reveal a negative surface soil moisture anomaly in 2003.

The results indicate that there was in general potential to monitor the spatial and temporal dimensions of the low surface soil water content early in 2003 using remote sensing techniques. Both remote sensing data sets indicate a consistent soil moisture decrease in early 2003. A good agreement between the observed surface soil moisture and soil moisture simulations from a land surface process model were found. An outlook to the use of remote sensing based soil moisture estimates for large scale monitoring of surface soil moisture trends is given. 